\title{
Eating behaviour, health locus of control and stages of change towards healthy eating among Portuguese undergraduate students
}

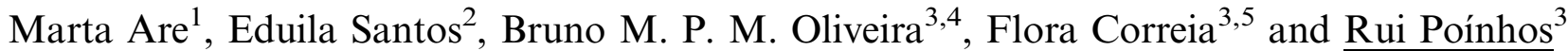 \\ ${ }^{1}$ Facoltà di Scienze Agrarie e Alimentari, Milano, Italy, \\ ${ }^{2}$ Centro Acadêmico de Vitórial Universidade Federal de Pernanbuco (CAVIUFPE), Bela Vista, \\ Vitória de Santo Antão - PE, Brazil, \\ ${ }^{3}$ Faculdade de Ciências da Nutrição e Alimentação, Universidade do Porto, Porto, Portugal, \\ ${ }^{4}$ Laboratório de Inteligência Artificial e Apoio à Decisão, Instituto de Engenharia de Sistemas e Computadores - \\ Tecnologia e Ciência, Porto, Portugal and \\ ${ }^{5}$ Centro Hospitalar de São João, E.P.E. \& Unidade de Investigação e Desenvolvimento de Nefrologia, Faculdade de \\ Medicina, Universidade do Porto, Porto, Portugal
}

\begin{abstract}
Eating behaviour refers to quantitative and qualitative features of the selection and decision on the foods to be consumed. Knowledge on determinants of eating behaviour increases the success of actions and interventions aiming to promote healthy eating habits and to prevent diseases. Several constructs facilitate the comprehension of health-related changes, among which the Locus of Control (LoC) and Stages of Change (SoC). Our aim was to study the relationships between several dimensions of eating behaviour with the health LoC and SoC towards healthy eating among Portuguese higher education students. Data from 267 higher education students $(63.7 \%$ females) aged 18 to 27 years were assessed regarding health LoC (Health Locus of Control Scale; Ribeiro, 1994), SoC towards healthy eating (question and items from Kearney et al. (1999), adapted to refer specifically to the adoption of healthy eating) and eating behaviour. Emotional and external eating were measured using the Dutch Eating Behavior Questionnaire, flexible and rigid control of eating behaviour was measured with the Portuguese version of the subscales proposed by Westenhoefer et al. (1999), the Portuguese version of the Binge Eating Scale was used to assess binge eating severity, and eating self-efficacy was measured using the General Eating Self-Efficacy Scale. BMI was calculated using self-reported weight and height. No significant associations were found between BMI and health LoC. In the female subsample, i-LoC assessed through the factor "locus of control" was negatively associated with binge eating and positively with eating self-efficacy. However, we also found a negative association between eating self-efficacy and i-LoC assessed by the factor "other powerful". Among men, none of the eating behaviour dimensions presented an association with health LoC. Regarding SoC, participants in the maintenance stage presented lower external eating and binge eating (both sexes), lower emotional eating and higher eating self-efficacy (women) and dietary restraint (higher rigid control among men but higher flexible control among women), when compared to those in the pre-contemplation/ contemplation stages. Our results suggest that SoC and LoC may be useful to achieve deeper knowledge on eating behaviour. Their assessement may also help designing early and sex-directed (namely regarding the different types of dietary restraint) programs and interventions focusing eating behaviour.
\end{abstract}

\section{Conflict of Interest}

There is no conflict of interest. 